\title{
Sustainable food systems link growers to new consumer markets in California
}

IN the last decade, Californians at every step of the food chain have pioneered new, sustainable systems of cultivation, marketing and distribution that promise to be more economically viable, environmentally sound and socially just. Four crises have driven these changes: (1) an epidemic rise in obesity, now a leading cause of preventable death; (2) a need for social justice in the food system, including reforms of working conditions, adequate wages for farm and factory workers, and food security for innercity residents; (3) a depletion of our natural resources, particularly water, on which California depends for many crops; (4) increasing signs of global warming, high carbon emissions and unsustainable energy expenditures for food production. We currently use 10 kilocalories (kcals) of fossil fuel to produce $1 \mathrm{kcal}$ of food energy.

In addition, industrialization, globalization and economic concentration in the food and agricultural system have made it difficult for family farmers, especially mid-scale growers, to remain in business, and for consumers to access healthful, sustainably produced foods from their local areas.

Since 1990, the UC Division of Agriculture and Natural Resource's (ANR) Sustainable Agriculture Research and Education Program (SAREP) has addressed these concerns by granting funds for dozens of food systems projects throughout the state (http://sarep.ucdavis.edu). Researchers have examined farmers' markets in low-income communities (see page 149), regional marketing organizations, regional processing facilities, food policy councils, year-round employment for agricultural workers, and urban gardening programs.

The new Agricultural Sustainability Institute (ASI) at UC Davis has now become the hub for a wide variety of campus programs that have advanced sustainable food systems for the last 20 years, including the Student Farm, the Sustainable Agriculture Farming Systems (SAFS) Project and the Longterm Research on Agricultural Systems (LTRAS) Project (see page 149). ASI has also been delegated with the responsibility for managing ANR's systemwide SAREP program.

SAREP and ASI have embarked on two new participatory research and extension projects; both will help satisfy a growing demand for foods that leave a smaller "carbon footprint," while simultaneously providing new markets for regional growers. The first project partners SAREP with the UC Santa Cruz Agroecology and Sustainable Food Systems Program (see page 152), the UC Davis Department of Agricultural and Resource Economics and the nonprofit Community Alliance with Family Farmers to research new farm-to-institution (specifically colleges and universities) markets for regional growers (see page 154). Institutional vendors are the second largest sector of the U.S. food-service market, spending $\$ 30.9$ billion for food at schools and colleges and another $\$ 42.8$ billion in 2006 at institutions such

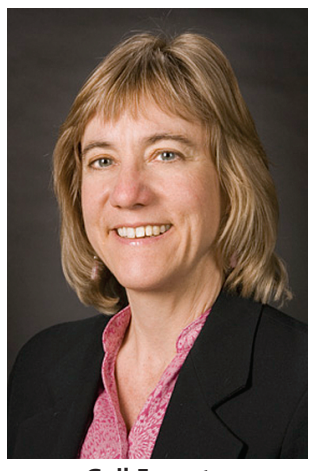

Gail Feenstra

Food Systems Analyst, UC Sustainable

Agriculture Research and Education Program

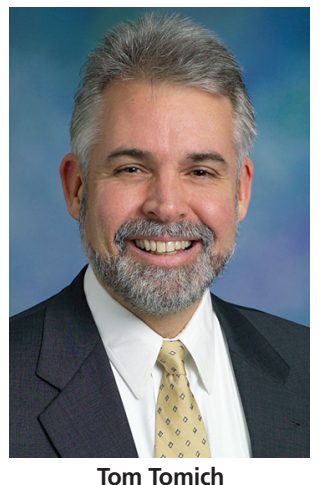

Tom Tomich

Director,

Agricultural Sustainability

Institute, UC Davis as hospitals, corporate cafeterias and airlines. In California alone, there are approximately 21,000 educational and health care institutions that provide meals to consumers daily, yet little is understood about this emerging market.

To date, the study team has conducted surveys that explore the extent to which new distribution infrastructures are able to supply an increasing demand for local, organic and sustainable food products, and what needs to be done to "ramp up" the system successfully. At an outreach event in July 2007, more than 100 growers, buyers, researchers and policymakers shared information and preliminary research results, and created new business opportunities. We expect the results will be used to strengthen this expanding initiative.

The second project is a partnership between ASI, SAREP, the Bon Appetit Management Company Foundation, the UC Davis Institute of Transportation Studies and several UC Davis departments. This project will analyze foods and provide recommendations for a "low-carbon diet," by gathering data on the embedded energy and carbon emissions associated with a variety of foods. The project will use a methodology called "life-cycle analysis," which includes energy inputs/emissions from farm to retail. In October 2007, an international symposium at UC Davis will gather input from European and national experts as well as UC researchers for a white paper and to form the framework of a collaborative research agenda.

These two initiatives, although in their early stages, are already revealing some key insights. First, sustainable food systems are complex and dynamic. It takes a multidisciplinary research and outreach effort to address the challenges and opportunities that arise. Second, partnerships among institutions of higher education, industry and nonprofit community groups ensure that the research is relevant and timely. Third, ongoing and new communication systems are important to increase the likelihood of cooperation between related food systems and to avoid redundancy.

To that end, the Agricultural Sustainability Institute has embarked on a strategic planning process that involves input from food and agricultural systems stakeholders across many levels. We invite participants to help us prioritize issues and embark on new research and outreach efforts. To engage in this process, please visit: http://asi.ucdavis.edu/strategicplanning.htm. 